\title{
Prostate Specific Antigen (PSA) Levels and its Correlation to Prostatic Lesions
}

\author{
Apurva Mangesh Londhe* and Anita Bharat Shah \\ Pathology department, Saifee Hospital, Maharshi Karve Marg, Mumbai-400004, Maharshtra, India
}

\begin{abstract}
Background: To correlate PSA levels with prostatic lesions and grade of Prostatic adenocarcinoma

Methods: The study includes male patients with lower urinary tract complaints, advised to get their PSA levels and Transrectal ultrasound (TRUS) guided prostatic biopsy done. Study design was observational and retrospective. Universal sampling method has been used for selection, during study period May 2015 to September 2016. Ethical clearance has been obtained from Medical Ethical Committee of Saifee Hospital. We received 116 TRUS biopsies in the described time frame. The relevant data for these were collected from the hospital and departmental records.

Results: Out of 116 cases, 57 cases were malignant and 59 cases were benign. Fifty-three (93\%) of the malignant cases and 54 (91.5\%) of the benign cases had PSA levels above $4 \mathrm{ng} / \mathrm{ml}$. Thus, association of PSA level and type of lesion was found to be statistically insignificant $(\mathrm{p}>0.05$ ). The mean PSA level was $19.67 \mathrm{ng} / \mathrm{ml}$ in Grade 1 Prostatic adenocarcinoma, $10.84 \mathrm{ng} / \mathrm{ml}$ in Grade 2 Prostatic adenocarcinoma, 21.07ng/ml in Grade 3 Prostatic adenocarcinoma, 39.06ng/ml in Grade 4 Prostatic adenocarcinoma and 399.26ng/ml in Grade 5 Prostatic adenocarcinoma. Thus, the mean PSA level increased as the grade increased but it was statistically not significant $(\mathrm{p}>0.05)$.
\end{abstract}

Conclusion: Serum PSA level as tumor marker has limitations. Thus, histopathological examination is more specific for correct diagnosis in clinically suspicious cases.

Keywords: Prostate Specific Antigen, Prostatitis, Prostatic adenocarcinoma

\section{Introduction}

Benign prostate hyperplasia, prostate carcinoma and prostatitis are three pathologic processes which frequently affect the prostate gland. ${ }^{[1]}$ One of the most interesting aspect of the prostate is that both benign and malignant tumors are hormone (androgen) dependent and are associated with significant morbidity and mortality in man..$^{[2]}$

Nearly 1 in 10 men in their 70s will have Acute Urinary Retention in the subsequent 5 years. As these disorders are common in elderly men; assessment and management of prostate is the important aspect in geriatrics practice and attracts research in gerontology. ${ }^{[2]}$ Prostate cancer is an important growing health problem, presenting a challenge to urologists, radiologists and pathologist. Currently, many men are identified as having early prostate cancer through the use of prostate specific antigen (PSA) screening. ${ }^{[3]}$ It is known that a raised PSA level can also occur in nonmalignant conditions like benign prostatic hyperplasia $(\mathrm{BPH})$, inflammation, diagnostic and surgical procedures. These conditions may mimic cancer and cause confusion in diagnosis. ${ }^{[4]}$ Thus, transrectal ultrasound (TRUS) guided biopsy of the prostate is the major method by which prostate cancer is diagnosed..$^{[5]}$

\section{Materials and Methods:}

The present study was undertaken in Histopathology department of Saifee Hospital, Mumbai.

It includes male patients with lower urinary tract complaints who were advised to get their PSA levels and TRUS guided prostatic biopsy done. Study design was observational and retrospective. Being an observational study, universal sampling method has been used for selection of study participants during study period May 2015 to September 2016. We received 116 TRUS biopsies in the described time frame. The relevant data of these were collected from the hospital and departmental records. Majority of the cases came as 6 core biopsies, each in different containers, 3 from right and 3 from left lobe of prostate.

They were sampled from periurethral zone, peripheral zone and central zone of either lobe of prostate and labelled. Right side of lobe was labelled as I and left side of lobe as II. Periurethral zone was labelled as 'A', Peripheral zone as ' $\mathrm{B}$ ' and central zone as ' $\mathrm{C}$ '. Few specimens were sent in a single container.

Special stain (ZN stain) and immunohistochemistry (HMW-CK, p63 and AMACR) were used in granulomatous prostatitis and suspicious lesions respectively. 
Ethical clearance has been obtained from Medical Ethical Committee of Saifee Hospital. Data entry was done in Excel and analysed with the help of statistician. Microsoft word and excel have been used to generate tables. Qualitative data is presented with the help of Frequency and Percentage table.

\section{Results}

Out of 116 cases, 57 cases were malignant and 59 cases were benign. Age wise, upto 49 years, 2 benign cases $(3.4 \%)$ and 2 malignant cases $(3.5 \%)$ were noted. In 50-70 years age range, 30 benign cases $(50.8 \%)$ and 22 malignant cases $(38.6 \%)$ were noted. The maximum number of cases belonged to the age group 70 years and above (60 cases ie $51.7 \%)$. Of these, 33 were malignant (57.9\%) and 27 were benign (45.8\%) group.

The spectrum of lesions in prostatic biopsy seen in our institution were as follows- Prostatic adenocarcinoma- 57 cases (49.14\%), Chronic prostatitis- 32 cases (27.59\%), Benign prostatic tissue- 15 cases $(12.93 \%)$, Acute prostatitis and Granulomatous prostatitis- 4 cases each (3.45\% each), Chronic prostatitis with microabscess- 2 cases $(1.72 \%)$, Chronic prostatitis with eosinophilia and chronic prostatitis with sheets of foamy histiocytes- 1 case each $(0.86 \%$ each). ZN stain was carried out on cases of granulomatous prostatitis. All turned out to be negative for tubercle bacilli. Broadly, the lesions can be distributed as- Benign prostatic tissue 15 cases (12.93\%), Prostatitis 44 cases (37.93\%) and Prostatic adenocarcinoma 57 cases (49.14\%).

In the malignant cases, ISUP 2014/ WHO $4^{\text {th }}$ edition (International Society of Urological Pathology 2014/ World Health Organisation $4^{\text {th }}$ edition) Grades 1 to 5 were seen. In few cases, different Gleasons score/Grades were noted in different cores in the same patient. In such cases, the highest Gleasons score/Grade has been considered and statistics have been carried out accordingly. Prostatic adenocarcinoma Grade 5 was present in 26 cases (45.61\%), Grade 4 in 11 cases $(19.3 \%)$, Grade 3 in 7 cases $(12.28 \%)$, Grade 2 in 4 cases (7.02\%) and Grade 1 in 9 cases (15.79\%).

Tables 1 and 2, show the association of PSA levels as per type of lesion. $53(93 \%)$ of the malignant cases and 54
(91.5\%) of the benign cases had PSA levels above $4 \mathrm{ng} /$ $\mathrm{ml} .7 \%$ malignant cases had PSA levels upto $4 \mathrm{ng} / \mathrm{ml}$. Thus, association of PSA levels and type of lesion is found to be statistically insignificant ( $\mathrm{p}>0.05)$.

Table 3 shows the distribution PSA level as per grade of Prostatic adenocarcinoma. Pearson Chi Square test was carried out to associate PSA level with Grade of Prostatic adenocarcinoma. Test value was 20.463(a), degree of freedom was $12, \mathrm{P}$ value was 0.059 . Thus, association of PSA level with Grade of adenocarcinoma was found to be insignificant $(\mathrm{p}>0.05)$.

For Grade 1, the minimum PSA level was $0.18 \mathrm{ng} / \mathrm{ml}$, the maximum PSA level was $54.42 \mathrm{ng} / \mathrm{ml}$ and the mean PSA level was $19.67 \mathrm{ng} / \mathrm{ml}$.

For Grade 2, the minimum PSA level was $6.06 \mathrm{ng} / \mathrm{ml}$, the maximum PSA level was $18.58 \mathrm{ng} / \mathrm{ml}$ and mean PSA level was $10.84 \mathrm{ng} / \mathrm{ml}$.

For Grade 3, the minimum PSA level was $2.98 \mathrm{ng} / \mathrm{ml}$, the maximum PSA level was $70.77 \mathrm{ng} / \mathrm{ml}$ and mean PSA level was $21.07 \mathrm{ng} / \mathrm{ml}$.

For Grade 4, the minimum PSA level was $4.50 \mathrm{ng} / \mathrm{ml}$, the maximum PSA level was $102.10 \mathrm{ng} / \mathrm{ml}$ and mean PSA level was $39.06 \mathrm{ng} / \mathrm{ml}$.

For Grade 5, the minimum PSA level was $0.38 \mathrm{ng} / \mathrm{ml}$, the maximum PSA level was $2,521.58 \mathrm{ng} / \mathrm{ml}$ and mean PSA level was $399.26 \mathrm{ng} / \mathrm{ml}$.

\section{Discussion}

Out of the 116 cases that were studied, 59 cases were benign and 57 were malignant. In present study, 50.86\% cases were benign and $49.14 \%$ cases were malignant, comparable to $60.91 \%$ benign cases and $37.27 \%$ malignant cases in the study done by Varsha Khant et al (2017). ${ }^{[6]}$ Another study by Dr. Atchyuta .M et al (2016) ${ }^{[7]}$ had $79.7 \%$ benign cases and 20.3\% malignant cases. Geographical location and environment may account for this uneven distribution of benign and malignant lesions. The above studies by Varsha Khant et al (2017) ${ }^{[6]}$ and Atchyuta .M et al $(2016)^{[7]}$ included prostatic biopsies as well as prostate

Table 1: PSA level in malignant and benign lesions.

\begin{tabular}{|l|c|c|c|}
\hline \multirow{2}{*}{ PSA level (nanogram/millilitre) } & \multicolumn{2}{|c|}{ Type of Lesion } & \multirow{2}{*}{ Total } \\
\cline { 2 - 4 } & Malignant & $54(91.5 \%)$ & $107(92.2 \%)$ \\
\hline Above $4 \mathrm{ng} / \mathrm{ml}$ & $53(93.0 \%)$ & $5(8.5 \%)$ & $9(7.8 \%)$ \\
\hline Upto $4 \mathrm{ng} / \mathrm{ml}$ & $4(7.0 \%)$ & $\mathbf{5 9 ( 1 0 0 . 0 \% )}$ & $\mathbf{1 1 6 ( 1 0 0 . 0 \% )}$ \\
\hline Total & $\mathbf{5 7 ( 1 0 0 . 0 \% )}$ & \multicolumn{1}{|c|}{ Benign } & \\
\hline
\end{tabular}


Table 2: Association of PSA level with benign and malignant lesions

\begin{tabular}{|l|c|c|c|c|}
\hline Chi-Square test & Value & df & P Value & Association is \\
\hline Pearson Chi-Square & 0.086 & 1 & 0.769 & Not Significant \\
\hline Fisher's Exact Test & & & 1.000 & Not Significant \\
\hline
\end{tabular}

Table 3: Distribution of PSA levels in different Grades of Prostatic adenocarcinoma.

\begin{tabular}{|c|c|c|c|c|c|c|}
\hline \multirow{2}{*}{$\begin{array}{l}\text { PSA level } \\
\text { (nanogram/millilitre) }\end{array}$} & \multicolumn{5}{|c|}{ Grade } & \multirow{2}{*}{ Total } \\
\hline & 1 & 2 & 3 & 4 & 5 & \\
\hline Upto 4 ng/dl & $2(22.2 \%)$ & $0(0.0 \%)$ & $1(14.3 \%)$ & $0(0.0 \%)$ & $1(3.8 \%)$ & $4(7.0 \%)$ \\
\hline 4 to $10 \mathrm{ng} / \mathrm{ml}$ & $3(33.3 \%)$ & $2(50.0 \%)$ & $2(28.6 \%)$ & $3(27.3 \%)$ & $1(3.8 \%)$ & $11(19.3 \%)$ \\
\hline 10 to $20 \mathrm{ng} / \mathrm{ml}$ & $1(11.1 \%)$ & $2(50.0 \%)$ & $2(28.6 \%)$ & $1(9.1 \%)$ & $5(19.2 \%)$ & $11(19.3 \%)$ \\
\hline Above 20 ng/ml & $3(33.3 \%)$ & $0(0.0 \%)$ & $2(28.6 \%)$ & $7(63.6 \%)$ & $19(73.1 \%)$ & $31(54.4 \%)$ \\
\hline Total & $9(100.0 \%)$ & $4(100.0 \%)$ & $7(100.0 \%)$ & $11(100.0 \%)$ & $26(100.0 \%)$ & $57(100.0 \%)$ \\
\hline
\end{tabular}

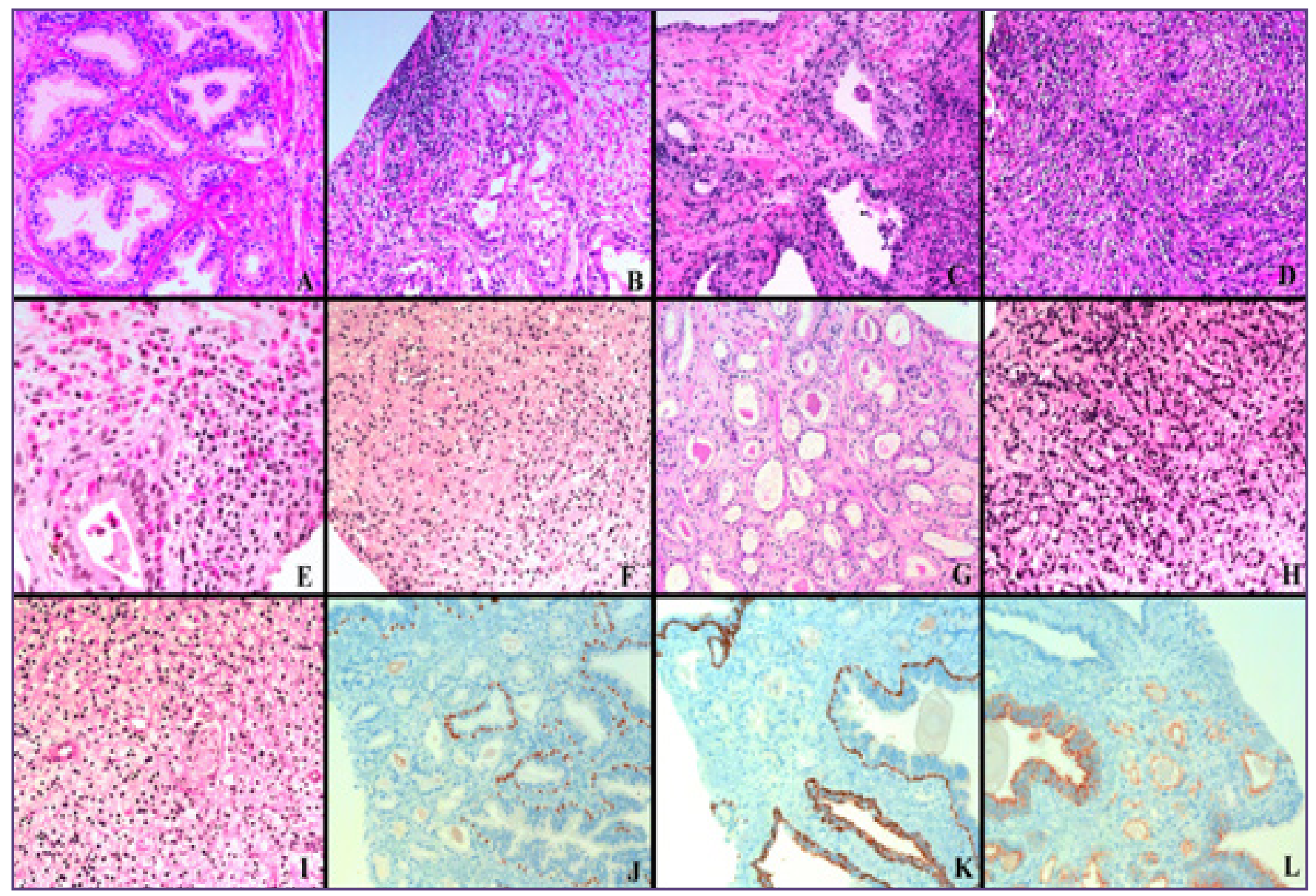

Fig. 4: A- Benign Prostatic tissue (H\&E, 20X), B- Chronic prostatitis(H\&E, 20X),C-Acute prostatitis (H\&E, 20X), DGranulomatous prostatitis(H\&E, 20X), E- Chronic prostatitis with eosinophilia (H\&E, 40X), F- Chronic prostatitis with foamy histiocytes (H\&E, 20X), G- Prostatic adenocarcinomaGleasons score 3 (H\&E, 20X), H- Prostatic adenocarcinomaGleasons score 4 (H\&E, 20X), I- Prostatic adenocarcinomaGleasons score 5 (H\&E, 20X).On Immunohistochemistry(20X), J- suspicious focus of glands with negative nuclear staining of p63, K- suspicious focus of glands with negative cytoplasmic staining of HMW CK (marker of basal cell), L- AMACR positivity in suspicious malignant glands. 
chips(Transrectal Urethral Resection of Prostate chips), whereas we included only TRUS biopsies. This can also account for more benign cases in these studies.

The lesions were classified into three main categoriesBenign prostatic tissue, Prostatitis and Prostatic adenocarcinoma. Benign prostatic tissue was seen in $12.93 \%$ cases in present study, $85.8 \%$ in a study by Kshitij et al (2011) ${ }^{[8]} 64.48 \%$ in a study by Azmi A. Haroun et al (2011) ${ }^{[9]} 56 \%$ in a study by Jasani et al $(2012)^{[3]}$ and $38 \%$ in a study by Bedarshi Banerjee et al (2016). ${ }^{[10]}$ Prostatic adenocarcinoma was seen in $49.14 \%$ cases in present study, $8.35 \%$ in a study by Kshitij et al (2011), ${ }^{[8]} 27.1 \%$ in a study by Azmi A. Haroun et al (2011), ${ }^{[9]} 32 \%$ in a study by Jasani et al (2012) ${ }^{[3]}$ and $15 \%$ in a study by Bedarshi Banerjee et al (2016). ${ }^{[10]}$

Prostatitis was seen in $37.93 \%$ cases in present study, $0.64 \%$ in a study by Kshitij et al $(2011),{ }^{[8]} 2.7 \%$ in a study by Jasani et al (2012) ${ }^{[3]}$ and $37 \%$ in a study by Bedarshi Banerjee et al (2016). ${ }^{[10]}$ The above mentioned studies included prostate chips (TURP) as well. TURP is the gold standard of surgical treatment for benign prostatic hyperplasia. ${ }^{[11]}$ Thus, more percentage of benign lesions were found in these studies and greater percentage of malignant lesions were found in present study as compared to the above mentioned studies.

Prostatic Intraepithelial Neoplasm (PIN) was reported in few studies like by Bedarshi Banerjee et al (2016), ${ }^{[10]}$ Jasani et al (2012) ${ }^{[3]}$ and Kshitij et al (2011). ${ }^{[8]}$ These studies predominantly included prostate chips (TURP). In TURP specimens, the entire part of gland is sampled and examined under microscope, thus allowing more chances of diagnosing PIN as it may occur in small foci within a gland, which might go unnoticed in a biopsy, hence limiting the usefulness of prostatic biopsy. ${ }^{[10]}$

The cases of prostatic adenocarcinoma were graded according to the new ISUP/WHO classification 2014 in present study. Nine cases of Grade 1(15.79\%), 4 cases of Grade 2(7.02\%), 7 cases of Grade 3(12.28\%), 11 cases of Grade 4(19.30\%) and 26 cases of Grade 5(45.61\%) were reported. In the study done by Manjit Singh Bal et al (2013), ${ }^{[12]}$ Gleason score 5-7 were seen in $62.71 \%$ cases. The next Gleason score was $2-4$, seen in $23.72 \%$ cases (Total $86.43 \%$ ) and in $13.55 \%$ cases the Gleason score was 8-10. In the study done by Atchyuta .M et al (2016), ${ }^{[7]}$ Gleason grade 3 was the most common primary pattern in their study. The most common secondary pattern was Gleason grade 4. Thus, the most common Gleason's score was 7 in $43 \%$ cases, 5 in $17 \%$ of cases, 8 and 9 in $12 \%$ of cases each (Total 24\%), 6 and 4 in $8 \%$ of cases.
However, in present study, Grade 4 and 5 (Gleasons score 8 and 9) were most common, accounting for $64.91 \%$ of the malignant cases. Grade 1-3 were seen in $35.09 \%$ cases.

Only the cases with PSA levels were included. PSA levels in benign and malignant lesions were compared to other studies. In present study, PSA levels upto $4 \mathrm{ng} / \mathrm{ml}$ was found in $8.5 \%$ of benign cases. Rest $91.5 \%$ had PSA level above $4 \mathrm{ng} / \mathrm{ml}$. In comparison, study done by Jasani et al (2012), ${ }^{[3]}$ $62.6 \%$ of benign cases had PSA upto $4 \mathrm{ng} / \mathrm{ml}$ while $37.02 \%$ benign cases had PSA level above $4 \mathrm{ng} / \mathrm{ml}$.

Normal levels of serum PSA vary according to the age of the patient, in several disease processes like prostate cancer, prostatic intraepithelial neoplasia and prostatitis. ${ }^{[10]}$ Serum PSA levels are slightly elevated in cases of Benign Prostatic Hyperplasia (BPH) because of prostate tissue specific protease property of PSA. ${ }^{[13]}$ Kiehl and associates $(2001)^{[14]}$ in their study also concluded that BPH and prostatitis is associated with PSA elevation when glandular epithelium is disrupted. ${ }^{[14]}$

Thus, such high percentage of benign cases with PSA level above $4 \mathrm{ng} / \mathrm{ml}$ in our study can be attributed to more number of (acute, chronic and granulomatous) prostatitis cases. As high PSA levels can be found in benign conditions also, histopathology is necessary to confirm the diagnosis. In the malignant lesions, in present study $93 \%$ cases had PSA level above $4 \mathrm{ng} / \mathrm{ml}$ comparable to other studies, Sladana et al (2004) $)^{[13]}$ and Jasani et al $(2012)^{[3]}$ had $97.5 \%$ cases and $98.2 \%$ cases with PSA level above $4 \mathrm{ng} / \mathrm{ml}$. In a study by Dr. Nirav Hingrajia(2015), ${ }^{[15]} 26.5 \%$ patients had PSA levels of $\geq 20 \mathrm{ng} / \mathrm{ml}$, of which $70 \%$ patients had adenocarcinoma, $30 \%$ patients had hyperplasia; one of the later had active prostatitis. It showed that patients with markedly elevated serum PSA levels are more likely to harbor adenocarcinoma in their biopsies than benign changes.

Likewise, majority of the malignant cases in present study had PSA level above $4 \mathrm{ng} / \mathrm{ml}$. However, a small percent, $7 \%$ (4 out of total 57 malignant cases) of the malignant cases had PSA level below $4 \mathrm{ng} / \mathrm{ml}$. The lowest PSA level of $0.18 \mathrm{ng} / \mathrm{ml}$ was seen in Grade 1 prostatic adenocarcinoma.

As a significant number of malignant cases (7\%) had low PSA levels (upto $4 \mathrm{ng} / \mathrm{ml}$ ), it is imperative to carry out a TRUS biopsy whenever a clinician palpates a suspicious nodule on per rectal examination. This will enable an accurate diagnosis and early carcinomas will be detected. Thus, serum PSA determination alone, has certain limitations for the diagnosis of prostate cancer.

Association of Gleasons grade and PSA level- The study done by Atchyuta .M et al (2016) ${ }^{[7]}$ showed that there is 
strong positive correlation between Gleason score given in prostatic adenocarcinomas and serum PSA values. The results were similar to the studies done by Karazanashvili G et al (2003) ${ }^{[16]}$ and Wei -Jen Shih et al (1992). ${ }^{[17]}$

In a study by Dr. Nirav Hingrajia (2015), ${ }^{[15]}$ it was observed that the levels of serum PSA increased with increasing Gleason grade and score of the tumor. In their study, majority of cancers $(76 \%)$ belonged to intermediate to high grade category. Similarly, scores were also moderate to high in majority of cases. Most of the patients having grade 3 or above showed markedly high levels of PSA.

In present study, $73.1 \%$ of Grade 5 Prostatic adenocarcinoma, $63.6 \%$ of Grade 4 Prostatic adenocarcinoma, $28.6 \%$ of Grade 3 Prostatic adenocarcinoma, $0 \%$ of Grade 2 Prostatic adenocarcinoma and $33.3 \%$ of Grade 1 Prostatic adenocarcinoma had PSA level $>20 \mathrm{ng} / \mathrm{ml}$.

The minimum PSA level of $0.18 \mathrm{ng} / \mathrm{ml}$ and maximum PSA level of $2,521.58 \mathrm{ng} / \mathrm{ml}$ was seen in Grade 1 and Grade 5 Prostatic adenocarcinoma respectively. The mean PSA level was $19.67 \mathrm{ng} / \mathrm{ml}$ in Grade 1 Prostatic adenocarcinoma, $10.84 \mathrm{ng} / \mathrm{ml}$ in Grade 2 Prostatic adenocarcinoma, 21.07ng/ $\mathrm{ml}$ in Grade 3 Prostatic adenocarcinoma, 39.06ng/ml in Grade 4 Prostatic adenocarcinoma and 399.26ng/ml in Grade 5 Prostatic adenocarcinoma. Thus, the mean PSA levels increased as the grade increased but it was statistically not significant ( $\mathrm{p}>0.05)$.

\section{Conclusion}

The study proves that histopathology is essential for detecting prostatic adenocarcinoma. Digital rectal examination findings and PSA levels alone cannot be depended upon. Hence, it is essential to carry out TRUS biopsy and do a histopathological analysis whenever a clinician palpates a hard nodule on per rectal examination. This will enable early diagnosis and treatment. Thus, improving the 5 year survival rate of the patient.

\section{Abbrevations}

$\mathrm{ng} / \mathrm{ml}$ - nanogram/milliliter

$\mathrm{SD} /$ StdDev- Standard Deviation

IHC- Immunohistochemistry

HMW CK- High Molecular Weight Cytokeratin

CK- Cytokeratin

AMACR- Alpha Methyl Acyl coARacemase

ZN stain- ZiehlNeelsen stain

H\&E- Haematoxylin\& eosin stain
No.- Number

df- Degrees of freedom

\section{References}

1. Wadgaonkar AR, Patil AA, Mahajan SV, Yengantiwar RP. Correlation of serum prostate specific antigen level in various prostatic pathology in elderly men. Int J Basic Appl Med Sci. 2013;3:274-81.

2. Maru AM, Makwana HH, Lakum NR, Chokshi T, Agnihotri A, Trivedi N, et al. Study on correlation between prostate specific antigen and various prostatic pathology. Int J Med Sci Public Health. 2014;3:735-7.

3. Jasmin HJ, Himani BP, Bijol G, Hetal VV, Kaushik B, et al. Diagnostic Utility of Prostate Specific Antigen for Detection of Prostatic Lesions. Int J Biomed Adv Res. 2012;3(4):2-6.

4. Lakhey M, Ghimire R, Shrestha R, Bhatta D. Correlation of serum free prostate-specific antigen level with histological findings in patients with prostatic disease. Kathmandu Univ Med J (KUMJ) [Internet]. 2010;8(30):158-63.

5. Lin CC, Huang WJS, Wu LJ, Chang YH, Lin ATL, Chen KK. Diagnosis of prostate cancer: Repeated transrectal prostate biopsy or transurethral resection. J Chinese Med Assoc. 2008;71(9):448-54.

6. Khant VS, Goswami H, Shah PY. Correlation of serum prostate-specific antigen level in various prostate pathology in elderly men. Journal of Medical Science and Public Health. 2017;6(2):257-61.

7. Atchyuta M, Krishna R, Latha PP, Renuka IV, Tejaswini V, Vahini G. Histological Spectrum of Prostatic Adenocarcinomas in Correlation with PSA Values. Indian Journal of Pathology and Oncology. 2016;3(March):2-7.

8. Kshitij A, Jyoti S, Agnihotri AS, et al. Utility of prostate specific antigen in different prostatic lesions,PSA assay. Pathology and laboratory medicine. Jun 2011; 3(1):18-23.

9. Haroun AA, Hadidy AS, Awwad ZM, Nimri CF, Waleed S. Utility of Free Prostate Specific Antigen Serum Level and its Related Parameters in the Diagnosis of Prostate Cancer. Saudi Journal of Kidney Diseases and Transplantation.2011;22(2):291-7.

10. Banerjee B, Iqbal B, Kumar H, Kambale T, Bavikar R. Correlation between prostate specific antigen levels and various prostatic pathologies. J Med Soc [Internet]. 2016;30(3):172.

11. Persu C, Georgescu D, Arabagiu I, Cauni V, Moldoveanu C, Geavlete P. TURP for BPH How Large is Too Large. Journal of Medicine and Life. 2010;3(4):3-7.

12. Bal MS, Kansal P, Singh H, Kaur N, Garg PK. Gleason 's grading in Tru-Cut biopsy specimens of prostate carcinoma. Archives of International Surgery. 2013;3(2):132-6.

13. Živković S. Correlation between prostate-specific antigen and histopathological difference of prostate carcinoma. Arch Oncol. 2004;12(3):148-51. 
14. Anusha AM, Ranjith S, Annamala PT. Correlation between Prostate Specific Antigen and Acid Phosphatase with Histopathological Findings in Various Prostatic Pathologies. SSRG Int J of Medical Sciences. 2015;2(6):6-11.

15. Hingrajia NM, Desai H, Goswami HM, Gosai RN. Histopathological Study of transrectal ultrasound guided biopsies of prostate in patients with raised serum prostate specific antigen. NHL Journal of Medical Sciences. 2015;4(1):70-4.

16. Karazanashvili G, Abrahamsson AP. Prostate specific antigen and human grandular kallikrein in early detection of prostate cancer. J Urol. 2003;169:445-57.

17. Wei-Jen S, MD, Kelly G, Bonnie M, MD, Judith C, Becky W, Journal Of the National Medical Association. 1992;84:1049-1050.

*Corresponding author:

Dr. Apurva Mangesh Londhe, Address- Plot No.-4, AudumbarHsg. Soc., Sainathnagar, Nigdi, Pune- 411044 INDIA

Phone: +91 9920151069

Email: apurva.londhe06@gmail.com

Financial or other Competing Interests: None. 